\title{
Effect of Blend Ratio on Quality Characteristics of Polyester/Cotton Blended Ring Spun Yarn
}

\author{
Manik P*, Majumder S and Hossain RK \\ Department of Textile Engineering, Daffodil International University, Bangladesh
}

ISSN: 2578-0271

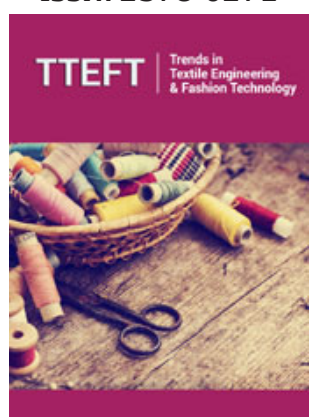

*Corresponding author: Manik P, Department of Textile Engineering, Daffodil International University, Bangladesh

Submission: 価 February 18, 2019

Published: 眥April 01, 2019

Volume 5 - Issue 1

How to cite this article: Manik $P$, Majumder S, Hossain R. Effect of Blend Ratio on Quality Characteristics of Polyester/Cotton Blended Ring Spun Yarn. Advancements Bioequiv Availab.5(1). TTEFT.000601.2019.

DOI: 10.31031/TTEFT.2019.05.000601.

Copyright@ Manik P, This article is distributed under the terms of the Creative Commons Attribution 4.0 International License, which permits unrestricted use and redistribution provided that the original author and source are credited.

\begin{abstract}
Cotton is a cool, soft, comfortable and is the principal clothing fiber of the world. Cloths made of this fiber absorb and release perspiration quickly, thus allowing the cloth to "breath." The advantages of polyester over cotton fibers are its strength, brightness, easy-care, low price, consistency in quality and availability. But it has low moisture regain (0.4\%) as compared to cotton (8\%). There is no perfect fiber that contains all the qualities of cotton and polyester mentioned above. In this context, blending is the technique to combine fibers which emphasizes the good qualities and minimizes poor qualities of the fibers. In blends of polyester/cotton, the fibers provide crease recovery, dimensional stability, tensile strength, abrasion resistance, moisture absorption, drape ability, etc. Different blend ratios of $\mathrm{P} / \mathrm{C}$ have been considered for experiment, i.e., $100 \%$ cotton, CVC $(60 \%$ cotton, $40 \%$ polyester $)$ and PC ( $50 \%$ cotton and $50 \%$ polyester). In this work, we studied the yarn characteristics with several P/C blend ratios of 30/s Ne. Here, the properties of blended ring spun yarns are compared with the same of $100 \%$ cotton yarn and the results are discussed in terms of the following quality parameters: Mass irregularity (CV\% and U\%), Thick, Thin \& Naps (IPI: Imperfection Index), CSP, single yarn strength and Hairiness.
\end{abstract}

Keywords: Polyester-cotton blend; Blending ratio; Yarn properties; Performance of blended yarn

\section{Introduction}

Blending of various fibers is extensively practiced for uplifting the performance and the aesthetic properties of cloth. Blended of natural fibers with man-made ones can provide the benefits of combining the good properties of both fiber components, such as comfort, softness, strength etc. These advantages also allow an increased variety of products to be made and deliver a stronger marketing advantage [1]. Reckoning of the performance of blended yarns has also been studied by numerous authors [2-5]. Natural fibers and their blends with man-made fibers improve the performance characteristics. They may be used for clothing, underwear, socks, hygienic, textile products as well as for composites [6]. Blending in the cotton spinning process has the aim to make yarn with suitable quality and cost. Use of adequate machines and techniques to select bales and knowledge of its characteristics is necessary to produce a good quality blend [7]. Years back, it had been a common practice to carry out the blending of natural and synthetic fiber in sliver form on the draw frame. The best blend in longitudinal direction was obtained in this way [8]. Department of Textile Engineering, Bangladesh. Li \& Yen [9] investigated that, fiber properties have a significant effect on yarn strength. However, Nawaz [10] concluded that the gradual decrease in yarn strength occurs as the share of polyester fibers in the blend decreases. Anandjiwal \& Goswami [11] suggested that blending dissimilar fibers lead to their non-uniform distribution throughout the yarn cross section, which in turn, lead to preferential migration depending on both fiber properties and mechanism of spinning process adopted. Therefore, the present study was carried out to figure out the effect of polyester/cotton blend ratio on quality characteristics of resultant yarn.

\section{Methodology}

The study was conducted in a well-known spinning mill situated at Gazipur, Dhaka, Bangladesh to see the quality of polyester-cotton blended yarn with respect to blending ratio. In Table $1 \& 2$ the details of the machineries and equipment's, used in this study, is given. For 
the purpose of experiencing the quality of polyester-cotton blended yarn the following cotton and polyester samples are consider, which are shown in Table 3-5 in details. After having the cotton and polyester with mentioned mixing ratio, the resultant yarn was observed for testing the performance depending on the blending ratio. Uster ${ }^{\circledR}$ evenness tester 4 was used to have the quality parameters and performance of the polyester-cotton blended yarn. Here, three types of blend ratio were considered for yarn count of 30 s', i.e., KW (100\% Cotton), CVC (60\% cotton $+40 \%$ polyester $)$ and PC ( $50 \%$ cotton $+50 \%$ polyester). The comparison of quality parameters of these three blends was subjected in this study, which is given in Table $6 \& 7$.

Table 1: Detailed overview of the production machineries use is given.

\begin{tabular}{|c|c|c|c|}
\hline \multicolumn{2}{|c|}{ Model } & \multicolumn{2}{c|}{ Manufacturer } \\
\hline Mniflock & Blow room (Cotton) & Rieter & Switzerland \\
\hline Uniclean & A 1/2 & Rieter & Switzerland \\
\hline Unimix & B7/3R & Rieter & Switzerland \\
\hline ERM-III & B 5/5 & Rieter & Switzerland \\
\hline Condenser & & Rieter & Italy \\
\hline Loptex & & Optosonic & Germany \\
\hline Dustex & SP-DX & Trutzschler & Germany \\
\hline Bale Opener (Polyester) & CS & Trutzschler & Germany \\
\hline Tuftomat (Polyester) & TO-T1 & Trutzschler & Rieter \\
\hline Carding (Cotton) & C-50, C-60 & Cross roll & China \\
\hline Carding (Polyester) & MK-6D & Cross roll & China \\
\hline Draw Frame & DX7AH, DX8 \& DX8-LT & Toyota & Japan \\
\hline Simplex & FL-100 & Howa & Muratec \\
\hline Ring Frame & UA33F & Japan \\
\hline Winding & Japan & \\
\hline
\end{tabular}

Table 2: Detailed overview of the testing equipment's used Table 3: Mixing ratio of cotton fiber is given. is given.

\begin{tabular}{|c|c|}
\hline Testing Equipments & Origin \\
\hline Uster $®$ HVI Spectrum, Zellweger Uster & Switzerland \\
\hline Uster ${ }^{\circ}$ AFIS Pro, Zellweger Uster & Switzerland \\
\hline Uster ${ }^{\circledR}$ Evenness Tester 4, Zellweger Uster & Switzerland \\
\hline Uster ${ }^{\circledR}$ Auto Sorter 4, Zellweger, Uster & Switzerland \\
\hline Uster ${ }^{\circledR}$ Tensojet 4 & Switzerland \\
\hline Electronic Wrap Reel & Indian \\
\hline Lea Strength Tester & Indian \\
\hline
\end{tabular}

\begin{tabular}{|c|c|c|c|}
\hline \multicolumn{4}{|c|}{ Cotton Used } \\
\hline Origin & Percentage (\%) & MIC & Color Grade \\
\hline Uganda & $17 \%$ & 4.15 & $33-2$ \\
\hline Zambian & $20 \%$ & 4.08 & $32-1$ \\
\hline Togo & $4 \%$ & 4.01 & $31-3$ \\
\hline Cameroon & $39 \%$ & 3.82 & $1-$ Nov \\
\hline Benin & $11 \%$ & 3.86 & $31-3$ \\
\hline Memphis & $9 \%$ & 4.74 & $41-1$ \\
\hline
\end{tabular}

Table 4: Lab testing summary of cotton fiber is given.

\begin{tabular}{|c|c|c|c|c|c|c|c|c|c|c|}
\hline \multicolumn{6}{|c|}{ Cotton Identification } & \multicolumn{5}{|c|}{ HVI Test } \\
\hline Origin & SCI & Mic. & $\mathbf{M}$ & U\% & SFI & Strength & $+\mathbf{b}$ & $+\mathbf{R d}$ & CG & UHML \\
\hline Uganda & 147 & 4.15 & 0.84 & 84.2 & 2.4 & 32.7 & 10.8 & 69.7 & $33-2$ & 29.61 \\
\hline Zambian & 128 & 4.08 & 0.83 & 83 & 4.8 & 28.2 & 9.8 & 75.2 & $32-1$ & 27.38 \\
\hline Togo & 133 & 4.01 & 0.83 & 81.6 & 7.7 & 31.9 & 9.1 & 76.7 & $31-3$ & 27.15 \\
\hline Cameroon & 142 & 3.82 & 0.83 & 82.7 & 5.8 & 30.4 & 9.5 & 80.7 & $1-\mathrm{Nov}$ & 29.16 \\
\hline Benin & 126 & 3.86 & 0.83 & 81.7 & 7.2 & 28.9 & 9.1 & 76.2 & $31-3$ & 27.39 \\
\hline Memphis & 132 & 4.74 & 0.85 & 82.9 & 5.8 & 31 & 8 & 75.2 & $41-1$ & 29.19 \\
\hline
\end{tabular}

SCI: Spinning Consistency Index, Mic: Micron Aire Value, M: Maturity Ratio, U\%: Uniformity Ratio, SFI: Short Fiber Index, +b: Degree of Yellowness, +Rd: Degree of Reflexes, CG: Color Grade of Cotton, UHML: Upper Half Mean Length 
Table 5: Ratio of polyester fiber is given.

\begin{tabular}{|c|c|c|c|}
\hline \multicolumn{4}{|c|}{ Polyester Used } \\
\hline Origin & Percentage (\%) & Denier & Length \\
\hline Virgin (China) & $100 \%$ & 1.4 & $32 \mathrm{~mm}$ \\
\hline
\end{tabular}

Table 6: Uster test result is given.

\begin{tabular}{|c|c|c|c|c|c|c|c|c|c|}
\hline Nominal Count & CSP & U\% & CV\% & $\begin{array}{l}\text { DR 1.5m } \\
(5 \%)\end{array}$ & $\mathbf{H}$ & $\begin{array}{l}\text { Thin } \\
(-50 \%)\end{array}$ & $\begin{array}{c}\text { Thick } \\
(+50 \%)\end{array}$ & $\begin{array}{c}\text { Neps } \\
(+200 \%)\end{array}$ & IPI \\
\hline $\begin{array}{c}30 \mathrm{~s}^{\prime} \mathrm{KW}(100 \% \\
\text { Cotton) }\end{array}$ & 2457 & 11.35 & 14.41 & 22.76 & 4.98 & 4.25 & 126 & 216.25 & 346.5 \\
\hline $30 s^{\prime} \mathrm{CVC}(60 \%+40 \%)$ & 2902 & 10.11 & 12.8 & 13.96 & 4.66 & 1.25 & 50.25 & 150.55 & 202.05 \\
\hline $30 \mathrm{~s}^{\prime} \mathrm{PC}(50 \%+50 \%)$ & 3121 & 10.1 & 12.75 & 13.5 & 4.41 & 1.2 & 49.75 & 126.75 & 138.06 \\
\hline
\end{tabular}

KW: Carded Yarn for Weaving, CVC: Cheap Value Cotton, PC: Polyester-Cotton Blend, CSP: Count-Strength Product, CV\%: Coefficient of Variance, DR: Drawing Ratio, H: Hairiness Value, IPI: Imperfection Index

Table 7: Results of single yarn strength tester is given.

\begin{tabular}{|c|c|c|c|c|}
\hline Nominal Count & B. Force (cN) & Elongation (\%) & Tenacity (cN/Tex) & R. Work (N.cm) \\
\hline 30s' KW $(100 \%$ Cotton) & 324.1 & 3.98 & 16.47 & 379.2 \\
\hline $30 s^{\prime}$ CVC $(60 \%+40 \%)$ & 300.5 & 5.21 & 19.5 & 570 \\
\hline $30 s^{\prime}$ PC $(50 \%+50 \%)$ & 410.9 & 6.8 & 21.2 & 812 \\
\hline
\end{tabular}

B. Force: Breaking Force, R. Work: Work of Rupture

\section{Results and Discussion}

\section{Effect of polyester/cotton blend ratio on $u \%$ \& cv\%}

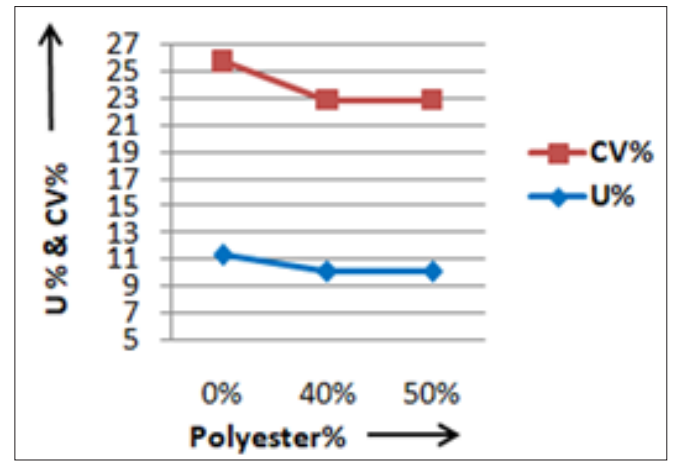

Figure 1: Effect of polyester/cotton blend ratio on $\mathrm{u} \%$ \& $\mathrm{cv} \%$.

Figure 1 shows the relationship between the yarn blend ratio and $\mathrm{U} \%$ \& $\mathrm{CV} \%$ for various blend ratios of cotton and polyester. It is clearly revealed in the graph that $\mathrm{U} \%$ \& $\mathrm{CV} \%$ decrease gradually with the increase in polyester proportion. We hereby infer that increase in polyester share in blend results in lower U\% and CV\% and that the increase proportion of polyester brings down yarn $\mathrm{U} \%$ and $\mathrm{CV} \%$ to an appreciable extent.

\section{Effect of polyester/cotton blend ratio on thick $+\mathbf{5 0} \%$ / km}

A relationship between the blend ratio and number of thin places in the yarn for the various blend ratios was found. It is observed that the number of thin places in the yarn decreases with the increase in the polyester proportion in the blend, which is shown in Figure 2.

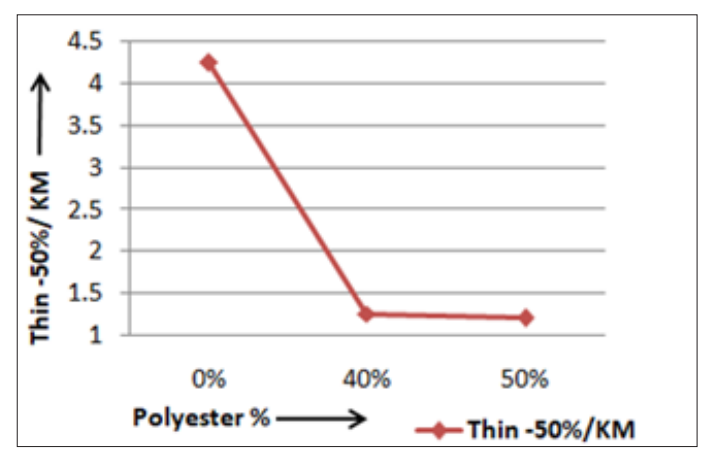

Figure 2: Effect of polyester/cotton blend ratio on thick $+50 \% / \mathrm{km}$.

Effect of polyester/cotton blend ratio on thin $-50 \% / \mathrm{km}$

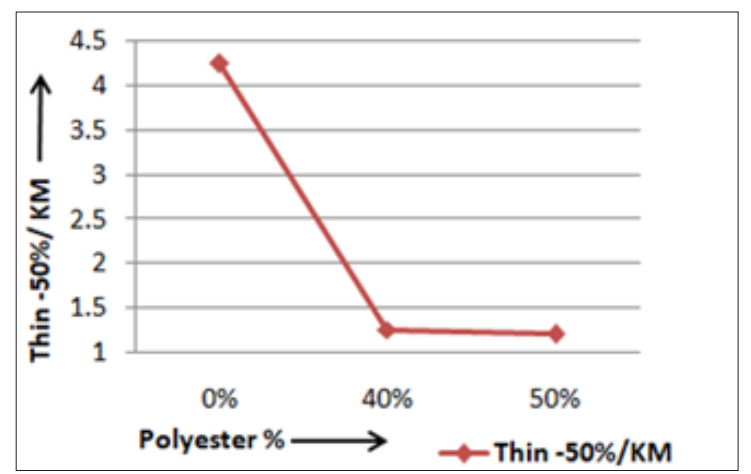

Figure 3: Effect of polyester/cotton blend ratio on thin $-50 \% / \mathrm{km}$.

From Figure 3, it is observed that there is a relation between the blend ratio and number of thin places in the yarn for the various blend ratios. It is also observed that the number of thin places in 
the yarn decreases with the increase in the polyester proportion in the blend.

\section{Effect of polyester/cotton blend ratio on NEPS 200\%/ km}

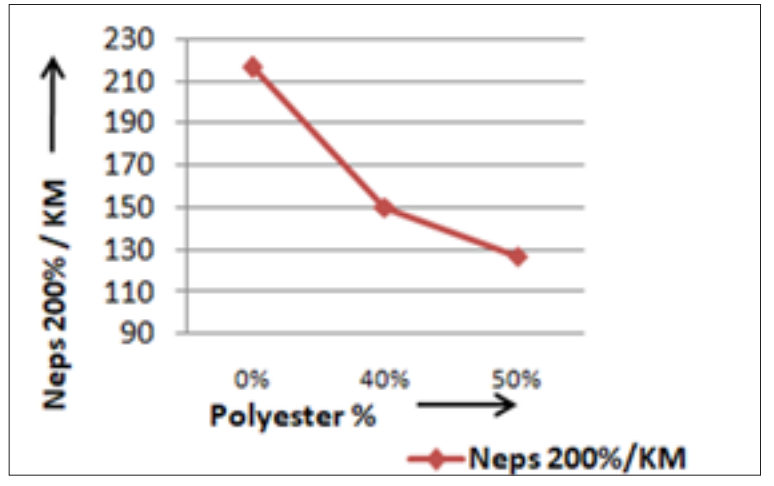

Figure 4: Effect of polyester/cotton blend ratio on NEPS $200 \% / \mathrm{Km}$.

The study revealed a relationship between the blend ratio and the NEPS $200 \%$ in the yarn per $\mathrm{km}$. There is an inverse nature of NEPS $(200 \% / \mathrm{km})$ with the increase in polyester proportion in the blend, which is shown in Figure 4.

\section{Effect of polyester/cotton blend ratio on IPI [thick} $(+50 \%)+$ thin $(-50 \%)+$ NEPS $(+200 \%)]$

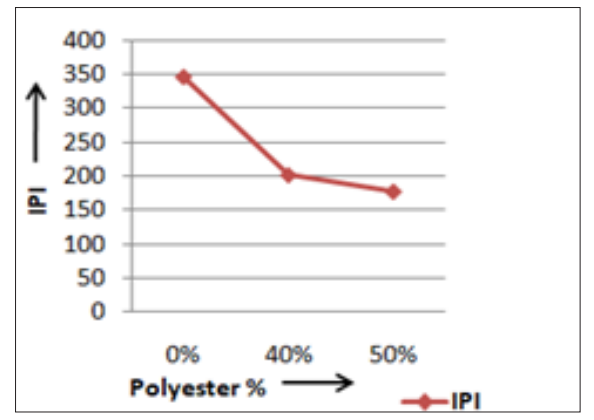

Figure 5: Effect of polyester/cotton blend ratio on IPI [thick $(+50 \%)+$ thin $(-50 \%)+\operatorname{NEPS}(+200 \%)]$.

Figure 5 shows the relation between the blend ratio and the IPI in the yarn. IPI graph also shows an inverse nature with the increase in polyester share in the blend. So, an increase in polyester share in the blend has much lower IPI (Imperfections).

\section{Effect of polyester/cotton blend ratio on CSP}

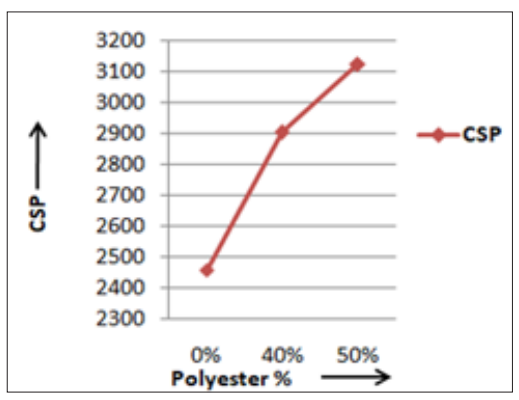

Figure 6: Effect of polyester/cotton blend ratio on CSP.
Figure 6 explains the strength values of the various blend ratio yarns. The graph reveals that increase in polyester proportion increases the yarn strength, which infers that an increase in polyester share in the blend has much higher CSP.

\section{Effect of polyester/cotton blend ratio on hairiness}

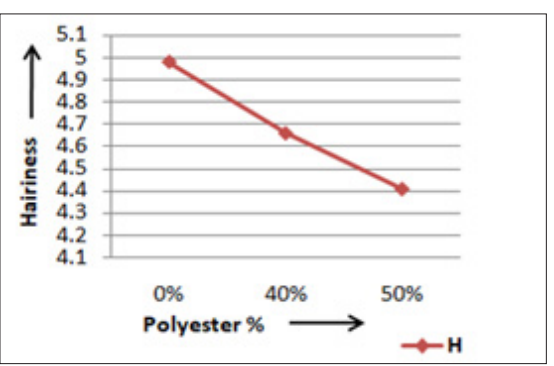

Figure 7: Effect of polyester/cotton blend ratio on hairiness.

A relation between blend ratio and hairiness index of the various blended yarns is stated in Figure 7 . The nature of the graph shows that, an increase in polyester share in the blend decreases the hairiness of the yarn.

\section{Effect of polyester/cotton blend ratio on strength}

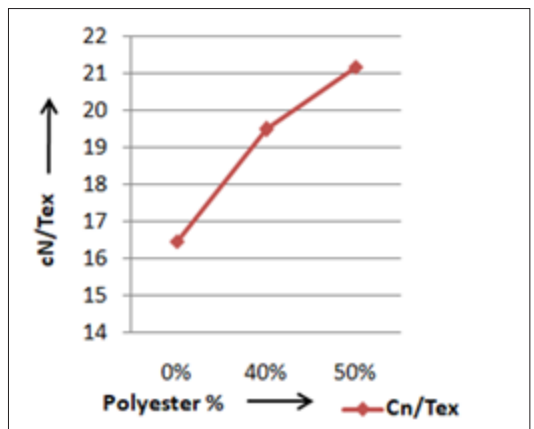

Figure 8: Effect of polyester/cotton blend ratio on strength.

Figure 8 determines the tenacity values of the blended yarns. The graph shows that the tenacity value increases with the increase in polyester proportion. We hereby infer that increase in polyester share in the blend has much higher strength.

\section{Effect of polyester/cotton blend ratio on elongation at} break

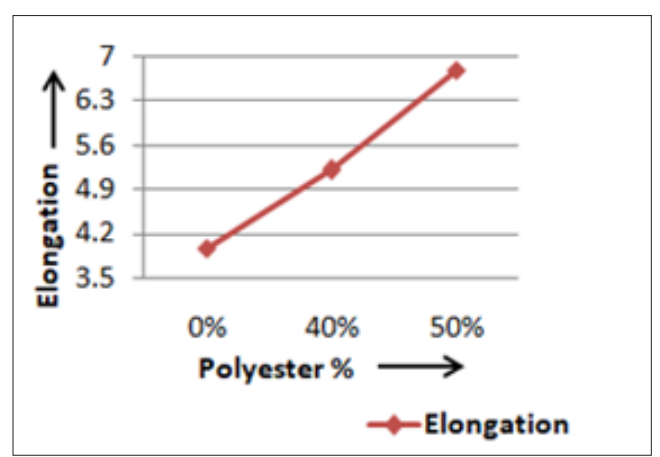

Figure 9: Effect of polyester/cotton blend ratio on elongation at break. 
The elongation of the yarn for the various blend proportions is stated in Figure 9. The graph reveals that, there is an increase in extension with an increase in the polyester share in blend.

\section{Effect of polyester/cotton blend ratio on work of rup- ture}

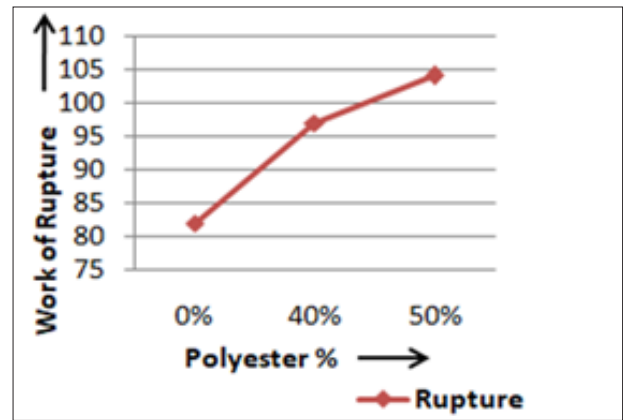

Figure 10: Effect of polyester/cotton blend ratio on work of rupture.

Figure 10 reveals the work of rupture values of the blended yarns, showing that the work of rupture value increases with the increase in polyester share in the blend.

\section{Conclusion}

The study was carried out to figure out the effect of polyester/ cotton blend ratio on quality characteristics of resultant yarn. The study reveals that, with the increase in polyester share in the blend, the overall quality parameters of yarns are improved. Some of them are U\%/CV\%, IPI, Hairiness, CSP and single yarn strength. At the same time, moisture regain $\%$ of the yarns decreases with the increase in polyester share in the blend; Such as, for $100 \%$ cotton: MR is $8.4 \%$, for $40 / 60$ PC: MR is 5.7\% and for 50/50 PC: MR is 5.0\%. However, depending on the end uses, the optimum percentage of polyester and cotton may be adjusted.

\section{Acknowledgement}

The authors are grateful to Yasmin Spinning Mills Ltd., Gazipur, Bangladesh for the support to the data collection required for this study.

\section{References}

1. Svetnickienè V, Čiukas R (2009) Investigation of friction properties of yarns from natural fibers. Mechanics 75(1): 73-76.

2. Pan N, Postle R (1995) Strengths of twisted blend fibrous structures: theoretical prediction of the hybrid effects. The Journal of the Textile Institute 86(4): 559-580.

3. Pan N, Chen K, Monego CJ, Backer S (2000) Studying the mechanical properties of blended fibrous structures using a simple model. Textile Research Journal 70(6): 502-507.

4. Kemp A, Owen JD (1995) The strength and behavior of nylon/cotton blended yarns undergoing strain. Journal of the Textile Institute 46(11): T684-T698.

5. Jianchun Z, Peixing F (1999) Predicting the tensile strength of lyocell/ PET blended yarns. ITB International Textile Bulletin 6(99): 28-30.

6. Ratnam TV, Narayana SK, Underwood C, Govindarajulu K (1968) Prediction of the quality of blended yarns from that of the individual components. Textile Research Journal 38(4): 360-365.

7. Béchir A, Hassen MB, Sakli F (2008) Adjustment of cotton fiber length by the statistical normal distribution: application to binary blends. Journal of Engineered Fibers and Fabrics 3(3): 35-46.

8. Klein W (1987) The technology of short staple spinning. The Textile Institute, Manchester, England, pp. 21-24.

9. Li Y, Yan H (1990) Measuring unevenness and blend ratio of yarns with microwave resonators. Textile Research Journal 60(1): 54-59.

10. Nawaz SM, Shahbaz B, Yousaf CK (1999) Effect of different blends with various twist factors on the quality of $\mathrm{p} / \mathrm{c}$ blended yarn. Pakistan Textile Journal 48(6): 26-29.

11. Anandjiwal R, Goswami BC, Charles KB, Bargeron JD (1999) Structural property relationship of blending cotton yarns made from low and high tenacity fibers. Textile Research Journal 69(2): 129-138. 